\title{
Continuous wound infusion of levobupivacaine after total abdominal hysterectomy with bilateral salpingo-0ophorectomy
}

\section{STELA MARIĆ 1 MIROSLAV BANOVIĆ ${ }^{1}$ KATA ŠAKIĆ ZDRAVČEVIĆ DUBRAVKA BARTOLEK ${ }^{3}$ LJILJANA ŠTEFANČIĆ ${ }^{1}$ DUBRAVKA KRLEŽA SUPIĆ \\ ${ }^{1}$ University Hospital for Tumors Anesthesiology and Intensive Care Zagreb, Croatia \\ ${ }^{2}$ University Hospital Center Zagreb, Anesthesiology and Intensive Care Zagreb, Croatia \\ ${ }^{3}$ University Hospital of Traumatology, Anesthesiology and Intensive Care Zagreb, Croatia \\ Correspondence \\ Marić Stela \\ University Hospital for Tumors, Anesthesiology and Intensive Care Zagreb, Croatia \\ E-mail:smaric5@yahoo.com}

Key words: continuous wound infusion analgesia, levobupivacaine: opioid analgesia, morphine, hysterectomy

\begin{abstract}
Background and Purpose: Blockade of nociceptive afferents by the use of continuous wound infiltration with local anesthetics may be beneficial in a postoperative multimodal pain management after total abdominal hysterectomy (TAH) with bilateral salpingo-oophorectomy (BSO). The role of continuous wound infusion of levobupivacaine for pain relief and postoperative recovery was evaluated.
\end{abstract}

Materials and Methods: Fifty female patients (ASA I-III) scheduled for TAH and BSO were divided in two equal groups during prospective, double-blinded, placebo-controlled trial. On completion of the operation, a multiorifice 20-gange epidural catheter was placed above the superficial abdominal fascia. Patients were randomly assigned to receive through the catheter $0.25 \%$ levobupivacaine (Group $L$ ) with $6 \mathrm{ml}$ bolus followed by an infusion of $7 \mathrm{ml} / \mathrm{h}$ during $48 \mathrm{~h}$, or the same protocol with $0.9 \% \mathrm{NaCl}$ (Group S). Simultaneously, patient-controlled analgesia provided intravenous morphine. All patients also received diclofenac $75 \mathrm{mg}$ every $12 \mathrm{~h}$ for $48 \mathrm{~h}$.

Results and Conclusions: Median Visual Analogue Scale (VAS) was satisfactory. Compared with suprafascial saline, levobupivacaine infusion reduced morphine consumption during the first $48 \mathrm{~h}$. The morphine consumption was significantly less $(P<0.001)$ in Group $L(6.91+/-3.17 \mathrm{mg})$ in comparison to Group $S(50.61+/-14.02 \mathrm{mg})$. Nausea was less in Group $L$. Time to recover the bowel function was significantly reduced in Group L. No side effects were observed. Postoperative pain control with continuous wound infusion of $0.25 \%$ levobupivacaine after TAH with BSO provides effective analgesia, decreases opioid requirements and reduces time to recover the bowel function.

\section{INTRODUCTION}

Z ffective postoperative analgesia is a prerequisite to enhance the reCovery process and reduce morbidity. As females are more at risk for severe postoperative pain (1), we need to improve perioperative pain management in those undergoing gynecological surgery. Pfannenstiel incision is well recognized as a source of persistent postoperative pain: $30 \%$ of patients undergoing that surgical approach complained of pain 2 years after the procedure ( $8 \%$ reporting severe pain impairing daily activities) (2). Local anesthetic wound infiltration is widely recognized as a useful adjunct in a multimodal approach to postoperative pain management $(3,4)$. A systematic review of randomized, controlled trials con- 
firmed the benefits and the safety of this technique, showing a very low incidence of complications (5). However, conflicting results have also been reported (6). After gynecological surgery patients complain of both somatic and visceral pain. Nonsteroidal anti-inflammatory drugs (NSAID) strongly potentiate opioids and are particularly effective to relieve the visceral component of pain (7). At our institution, morphine administered via a patient-controlled analgesic (PCA) device is the current standard for the provision of postoperative analgesia after total abdominal hysterectomy (TAH) with bilateral salpingoophorectomy (BSO). Although PCA morphine provides satisfactory analgesia, it is associated with adverse effects, such as fatigue, nausea, vomiting, ileus as well as the inability to mobilize because of drowsiness $(3,4)$.

Other methods of analgesia that have morphine-sparing effects are therefore frequently used to reduce postoperative morbidity.

The aim of the study was to assess the efficacy of continuous wound infusion with levobupivacaine in reducing morphine requirements, after TAH and BSO.

\section{MATERIAL AND METHODS}

Fifty ASA physical status I, II and III female patients undergoing TAH and BSO with Pfannenstiel incision were divided in two equal groups. They were included in prospective, double-blind study during six months period. Ethic Comity of University Hospital of Tumors approved the investigation. Patients with a history of clinically significant cardiovascular, pulmonary, hepatic, renal, neurological, psychiatric, metabolic disease, chronic pain or obesity were excluded from the study. A nurse who did not participate in the study was asked to mix the study drugs.

All patients were premedicated by midazolam 7,5 mg orally $1 \mathrm{~h}$ before the planned surgery. After arrival in the operating room, patients were randomly allocated to receive a continuous wound infusion of either $0.25 \%$ levobupivacaine (L Group) or $0.9 \%$ saline (S Group). Except for the medication delivered through the wound catheter, postoperative management was strictly identical for all patients.

After IV cannulation anesthesia was induced with fentanyl $1-2 \mu \mathrm{g} / \mathrm{kg}$ IV and propofol $2 \mathrm{mg} / \mathrm{kg}$ until loss of eyelash reflex. Tracheal intubation was performed after muscle relaxation with vecuronium $0,1 \mathrm{mg} / \mathrm{kg}$, and anesthesia was maintained with $1-2 \%$ sevoflurane in $33 \%$ mixture of oxygen-air. Surgical relaxation was maintained with IV vecuronium. Mechanical ventilation was used in a low flow system to maintain an end-tidal $\mathrm{CO}_{2}$ $4,5-5,5 \mathrm{kPa}$. The urinary bladder was catheterized. Sevoflurane concentration was adjusted to maintain adequate anesthetic depth as assessed clinically, and IV fentanyl was given intermittently as an analgesic when required. Residual neuromuscular blockade was reversed, if needed, with a mixture of atropine and neostigmine.

On completion of operation, a multiorifice 20-gauge epidural catheter (B. Braun, Melsungen, Germany) was placed by the surgeon above the superficial abdominal fascia, so that the tip was at the midpoint of the surgical wound and was secured on the skin with sterile tape. When the wound was closed, a $6 \mathrm{ml}$ bolus of test solution was administered through the catheter. The catheter was aseptically connected to infusion device (Braun, Germany) which was programmed to deliver either $7 \mathrm{ml} / \mathrm{h}$ $0,25 \%$ levobupivacaine or saline solution. All patients receive diclofenac $75 \mathrm{mg}$ IV and morfine $0,1 \mathrm{mg} / \mathrm{kg}$ IV, 30 minutes before conclusion the surgical procedure. After tracheal extubation, pain was assessed, and those patients with pain greater than 2 on a 4 -point verbal rating scale received intravenous boluses of $2 \mathrm{mg}$ morphine as titration, with 5-min intervals, until pain decreased to a maximum verbal rating scale of $1(0-$ no pain, 1 - mild pain, 2 moderate pain, and 3 - severe pain). A patient-controlled analgesia (PCA) device (Curlin Medical 6000 CMS, USA) was then connected to an intravenous infusion and set to deliver a $1 \mathrm{mg}$ dose of morphine with a 10 -min lockout interval. Evaluation started at the end of the wound closure. The primary endpoint was parenteral morphine consumption, which was measured during first $48 \mathrm{~h}$.

Time to return of gastrointestinal function was defined as the time from the end of surgery until the first bowel movement. Time until the first occurrence of flatus and first defecation were noted.

All side effects were recorded. The incidence of postoperative nausea requiring specific treatment with intravenous ondansetron $(4 \mathrm{mg})$, was noted.

Data were analyzed using Paired t- test and Mann -Whitney Rank Sum test. Statistical significance was accepted at $\mathrm{P}$ value less then 0.05 .

\section{RESULTS}

All enrolled patients successfully completed the study and were included in the main analysis.

Study groups were comparable and did not differ in demographic data.

Median VAS was satisfactory (VAS less than 4) in both groups.

Morphine consumption was significantly higher in the S Group. The mean total morphine consumption over the first 48 postoperative hours was significantly less in Group L $6.91+/-3.17 \mathrm{mg}$ in comparison to Group S $50.61+/-14.02 \mathrm{mg} ; \mathrm{P}<0.001$ (Paired $t$-test $P<0.001$ ). The total doses of intravenous morphine given as titration in the PACU during the first $6 \mathrm{~h}$ were $4,14+/-3,79$ $\mathrm{mg}$ in L Group and 19,3 +/-3,65 mg in S Group (Paired t-test $\mathrm{P}=0.001$ ) (Figure 1).

Incidence of postoperative nausea was significantly higher in S group 44\% vs.18\% in L group (Mann Whitney Rank Sum Test: $t=2200, p=0.025$ ) (Figure 2). These findings were expected and are likely to be related to increased morphine consumption in this group.

Time to recover the bowel function was significantly reduced in L Group. Time to the first flatus was $36.4+/-$ 


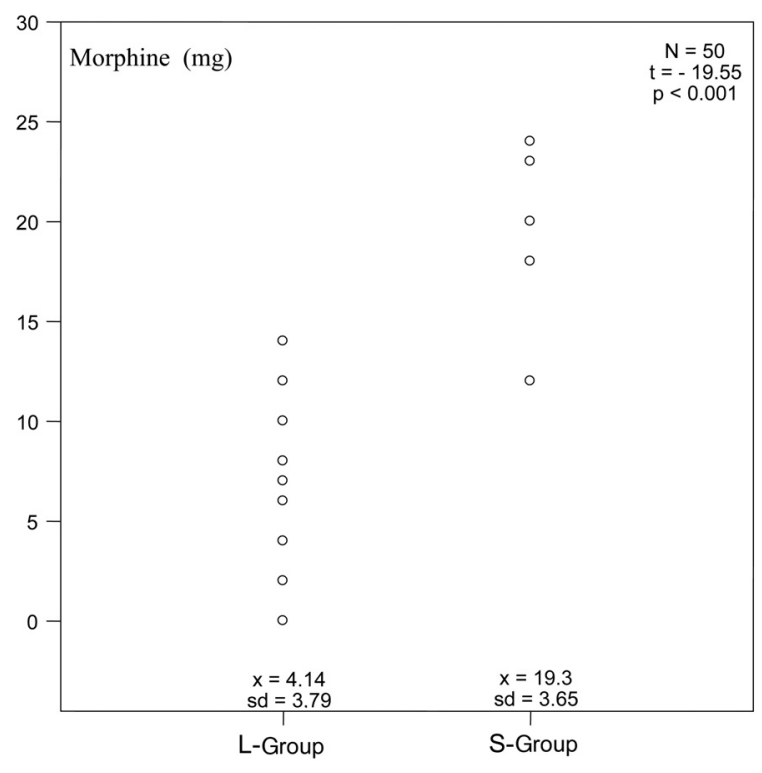

Figure 1. Postoperative morphine requirement $0-6 \mathrm{~h}$. Paired $t$-test: $t$ $=-19.55 ; p=0.001$.

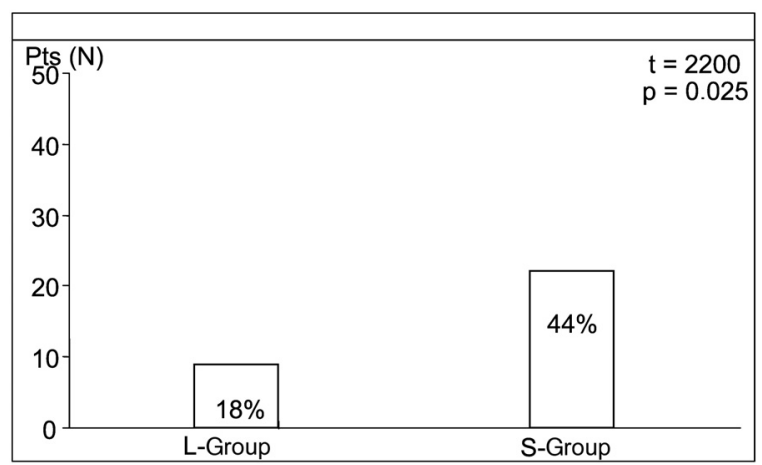

Figure 2. Incidence of postoperative nausea. Mann Whitney Rank Sum Test: $t=2200, p=0.025$.

$5.26 \mathrm{~h}$ in L Group and $53.76+/-6.273 \mathrm{~h}$ in S Group (Figure 3). First defecation was in L Group after $56.6+/-$ $13.47 \mathrm{~h}$ and in S Group 88,52 +/- 15,81 h (Mann Whitney Rank Sum Test: $t=1392.5 \mathrm{p}<0.001$ ) (Figure 4).

\section{DISCUSSION}

We found a significant opioid sparing effect in patients receiving continuous wound infusion of $0,25 \%$ levobupivacaine above the superficial abdominal fascia compared with placebo infusion for $48 \mathrm{~h}$. This was associated with a significant reduction in postoperative nausea $(\mathrm{PON})$. The time to recover the bowel function was also faster in L Group. Although the etiology of postoperative nausea and vomiting is multifactorial, we postulate that the decreased incidence of nausea in the $\mathrm{L}$ Group is probably caused by levobupivacaine - induced opioid sparing. No signs of local anesthetic toxicity or other side effects were reported by any of patients. TAH with BSO is associated with extensive surgical dissection

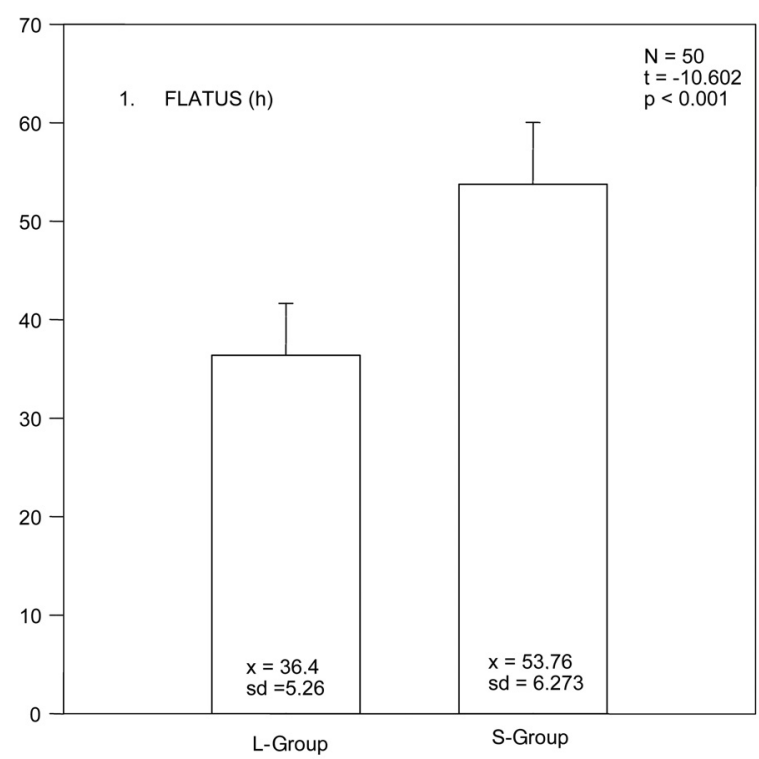

Figure 3. Time to first flatus. Mann Whitney Rank Sum Test $t=$ $-10,602, p<0,001$.

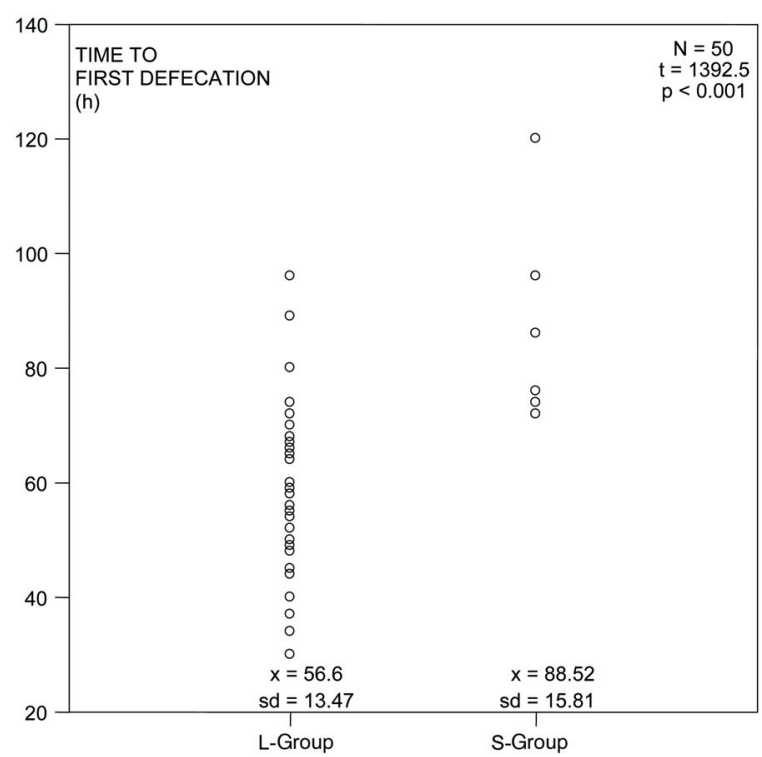

Figure 4. Time to first defecation. Mann Whitney Rank Sum Test: $t$ $=1392.5 p<0.001$.

and tissue damage. Hafizoglu MC et al. demonstrated that better postoperative analgesia is achieved with local anesthetic wound infusion above fascia compared with below fascia after abdominal hysterectomy (8). Pain after abdominal hysterectomy can be multifactorial. It is possible that somatic pain is the major cause of discomfort after TAH with BSO (9). Somatic pain is attenuated because, after local anesthetic infiltration into the surgical wound, these drugs modulate peripheral pain transduction by inhibiting the transmission of noxious impulses from the site of injury (10). The mechanism by which local anesthetics attenuate noxious impulses gen- 
erated by visceral tissues distant to the site of drug infiltration is more difficult to explain. Systemic absorption of local anesthetic drugs may induce a systemic analgesic effect and attenuate the initiation of the excessive inflammatory response $(11,12)$. Diclofenac as the part of multimodal approach is particularly effective to relieve the visceral component of pain (7). It would be interesting to find out the exact role of diclofenac in relieving the visceral pain. We also noticed in L Group that almost all rescue morphine was used in the first 6 postoperative hours; the background of this reason could be investigated further. We supposed that wound absorption of local anesthetic requires specific time to achieve analgesia.

In conclusion, in this double blind study, we were able to demonstrate a significantly smaller opioid consumption with levobupivacaine infused above fascia after TAH and BSO. This opioid sparing effect was associated with a reduced incidence of nausea, reduced time to recover the bowel function, and accelerated the postoperative recovery. Wound infusion analgesia is safe and simple method which making specific supervision unnecessary. It could therefore be considered as an interesting alternative to epidural or parenteral analgesia in this setting. Optimal rate and concentration of local anesthetic wound infusion and the mechanism of action require further investigation.

\section{REFERENCES}

1. KALKMAN C J, VISSER K, MOEN J et al. 2003 Preoperative prediction of severe postoperative pain. Pain 105: 415-23
2. LOOS M J, SCHELTINGA M R, MULDERS L G et al. 2008 The Pfannenstiel incision as a source of chronic pain. Obstet Gynecol 111. $839-46$

3. KEHLET H, DAHL J 2003 Anaesthesia, surgery, and challenges in postoperative recovery. Lancet 362: 1921-8

4. WHITE P 2005 The changing role of non-opioid analgesic techniques in the management of postoperative pain. Anesth Analg 101: S5-22

5. LIU S, RICHMAN J, THIRLBY R, WU C 2006 Efficacy of continuous wound catheter delivering local anesthetic for postoperative analgesia: a quantitative and qualitative systematic review of randomized controlled trials. J Am Coll Surg 203: 914-32

6. MOINICHE S, MIKKELSEN S, WETTERSLEV J, DAHL J B 1998 A qualitative systemic review of incisional local anesthesia for postoperative pain relief after abdominal operations. Br J Anesthesia 81: $377-383$

7. SIDDIK S M, AOUAD M T, JALBOUT M I, RIZK L B, KAMAR G H, BARAKA A S 2001 Diclofenac and/or propacetamol for postoperative pain management after cesarean delivery in patients receiving patient controlled analgesia morphine. Reg Anesth Pain Med 26 . $310-5$

8. HAFIZOGLU M C, KATIRCIOGLU K, OZKALKANLI M Y, SAVACI S 2008 Bupivacaine infusion above or below the fascia for postoperative pain treatment after abdominal hysterectomy. Anesth Analg 107: 2068-72

9. ZOHAR E, FREDMAN B, PHILLIPOV A, JEDEIKIN R, SHAPIRO A 2001 The analgesic efficacy of patient controlled bupivacaine wound instillation after total abdominal hysterectomy with bilateral-oophorectomy. Anesth Analg 93: 482-7

10. DAHL J, MOINICHE S, KEHLET H 1994 Wound infiltration with local anesthetics for postoperative pain. Acta Anaesthesiol Scand 38: 7-14

11. GROUDINE S B, FISHER H A, KAUFMAN R P, PATEL M K, WILKINS L J, MEHTA S A, LUMB P D 1998 Intravenous lidocaine speeds the return of bowel function, decreases postoperative pain, and shortens hospital stay in patients undergoing retropubic prostatectomy. Anesth Analg 86: 235-9

12. HERROEDER S, PECHER S, SCHOENHERR M E, KAULITZ G, HAHNENKAMP K, FRIESS H, BOETTIGER B W, BAUER H, DIJKGRAAF O G, DURIEUX METEMIC, HOLLMAN M W 2007 Systemic lidocaine shortens length of hospital stay after colorectal surgery. Ann Surg 246: 192-200 